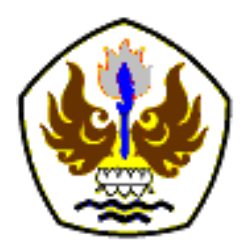

INFOMATEK

Volume 19 Nomor 2 Desember 2017

\title{
PERANCANGAN DAN PEMBUATAN ALAT UJI NDT ULTRASONIC TEST DENGAN METODE MICROCONTROLLER
}

\author{
Jojo Sumarjo *), Aa Santosa, Riko Purbowo \\ Jurusan Teknik Mesin \\ Universitas Singaperbangsa Karawang
}

\begin{abstract}
Abstrak: Alat ukur NDT merupakan suatu alat ukur tanpa merusak dari komponen yang diuji. Telah dibuat suatu alat ukur NDT jenis Ultasonic dengan menggunakan 2 motor penggerak dengan daya motor dan11,4 Watt 19,5 Watt dan menggunakan sensor yang diatur secara Microcontroller. Sensor tersebut mendeteksi keberadaan cacat logam dengan dua Probe. Pantulan dari probe tersebut akan membuat suatu grafik yang menjelaskan kedalaman dari cacat yang terjadi pada logam. Microcontroller menggunakan ATMEGA 8. Alat NDT tersebut dilakukan kalibrasi dengan alat ukur yang sudah standar dengan menggunakan dua buah material yaitu baja dan tembaga. Dari hasil kalibrasi didapat hasil untuk material baja pada alat ukur yang dibuat dengan material baja kecepatan rambatnya 3,13 sedangkan untuk tembaga 2,39. Sedangkan untuk alat ukur standar kecepatan rambat baja 0,89 dan untuk tembaga 0,59 . Perhitungan secara metoda Transversal untuk kecepatan rambat baja 3,13 dan tembaga 2,39 .
\end{abstract}

Kata kunci: NDT Ultrasonic, microcontroller, material

\section{PENDAHULUAN}

Inspeksi terhadap struktur material logam seperti baja sangat penting untuk mengetahui kondisi material dan melakukan tindakan preventif sebelum terjadinya kegagalan fungsi peralatan pada saat digunakan. Penurunan fungsi terjadi akibat keretakan, korosi, penyambungan, kelelahan penggunaan material dalam kurun waktu yang lama. Pengujian material dengan metode Non Destructive Test (NDT) adalah pengujian material tanpa menyebabkan kerusakan pada material, pengujian ini bertujuan untuk

*) jojosumarjo@gmail.com mendeteksi dan menentukan lokasi, ukuran dan karakteristik cacat (American Society for Non Destructive Testing [1]).

Terdapat banyak faktor yang mempengaruhi propagasi sinyal ultrasonic di dalam material. Menurut teori propagasi akustik, faktor utama yang mempengaruhi parameter pemantulan sinyal ultrasonic antara lain [1] :

1. Frekuensi dan bandwidth sinyal

2. ultrasonic

3. Jarak inspeksi yang dilalui

4. Posisi dan ukuran cacat

5. Propertis dari material. 
Suatu alat NDT dengan metode Ultrasonic yang lebih sederhana dan simple tetapi mempunyai tingkat akurasi yang baik dengan menggunakan Microcontroller. Sebuah chip yang berfungsi sebagai pengontrol rangkaian elektronik dan umumnya dapat menyimpan program di dalamnya. Microcontroller umumnya terdiri dari CPU (Central Processing Unit), memori, $1 / O$ tertentu dan unit pendukung seperti Analog-to-Digital Converter (ADC) yang sudah terintegrasi di dalamnya. Microcontroller AVR Atmega 8 merupakan salah satu jenis microcontroller yang di dalamnya terdapat berbagai macam fungsi. AVR Atmega 8 adalah microcontroller CMOS 8-bit berarsitektur AVR RISC yang memiliki 8 Kbyte in-System Programmable Flashyang digabungkan dengan LCD sebagai bentuk tampilan dari cacat yang dideteksi (Bartholommev [2]). Delphi suatu bahasa pemrograman (development language) yang digunakan untuk merancang suatu aplikasi program (Ryder [3]).

Non Destructive Test merupakan metode pengujian logam tanpa merusak, pengujian ini banyak dilakukan pada komponen atau bagian yang sedang digunakan sekalipun tanpa harus ada logam atau material sebagai sampel atau benda kerja. Di dalam inspeksi NDT harus mengetahui macam-macam cacat logam yang terjadi akibat dari proses pengerjaan misalnya: rolling/ forging, penuangan, pengelasan sehingga dapat memudahkan pemilihan peralatan yang tepat untuk mendeteksi cacatcacat tersebut (Classroom Training Handbook [4]).

Logam merupakan unsur kimia yang mempunyai sifat-sifat kuat, liat, keras, penghantar listrik dan panas, dan umumnya mempunyai titik cair yang tinggi. Logam banyak digunakan dalam berbagai industri manufaktur seperti proses pembuatan komponen mesin, dalam industri konstruksi seperti jembatan, pressure vessel dan heat exchanger. Logam digunakan karena mempunyai beberapa sifat yang bisa dimanfaatkan yaitu sifat mekanik, sifat teknologi, sifat fisik dan sifat kimia (William [5]).

\section{METODOLOGI PENELITIAN}

\subsection{Alat dan bahan yang digunakan}

a. Satu set komputer dengan program Delphi

b. Microcontroller

c. Probe atau sensor ultrasonic

d. Motor Steper 2 buah

e. LCD

f. Material sebagai sampel yang akan dilakukan pengujian

g. Rangka, sebagai dudukan alat uji

\subsection{Perancangan Alat Uji}

a. Skema Alat Uji Non Destructive Test Ultrasonic. 


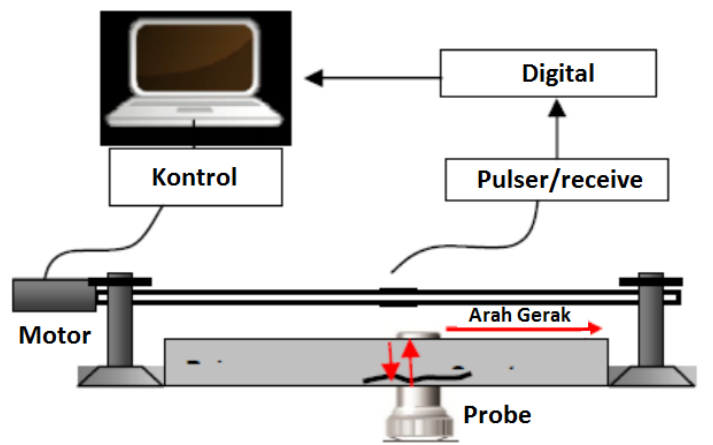

Gambar 1

Skema Alat Uji Non Destructive Test Ultrasonic (NDT)

b. Skema Alat Uji Non Destructive Test Ultrasonic

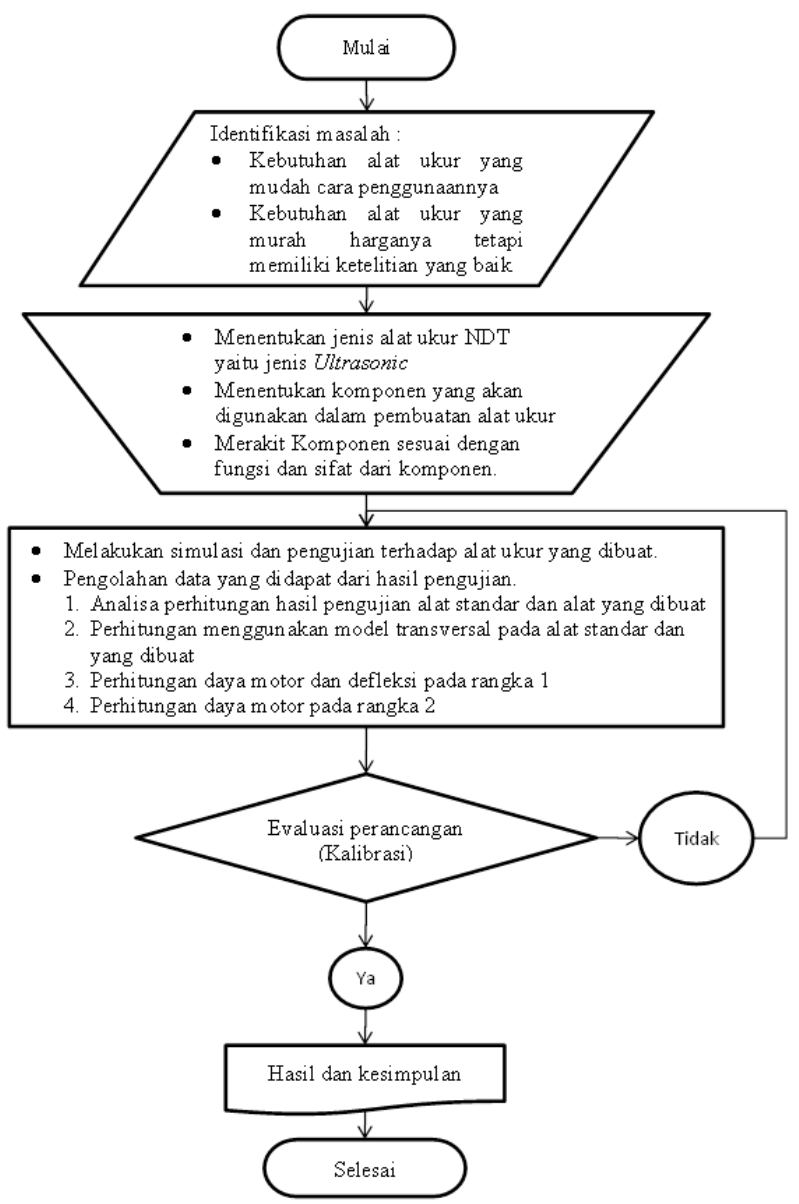

Gambar 2

Diagram Alir Pembuatan Alat Ukur NDT Ultrasonic 


\section{c. Perancangan Sistem Ultrasonic dan} mekanikal NDT ultrasonic

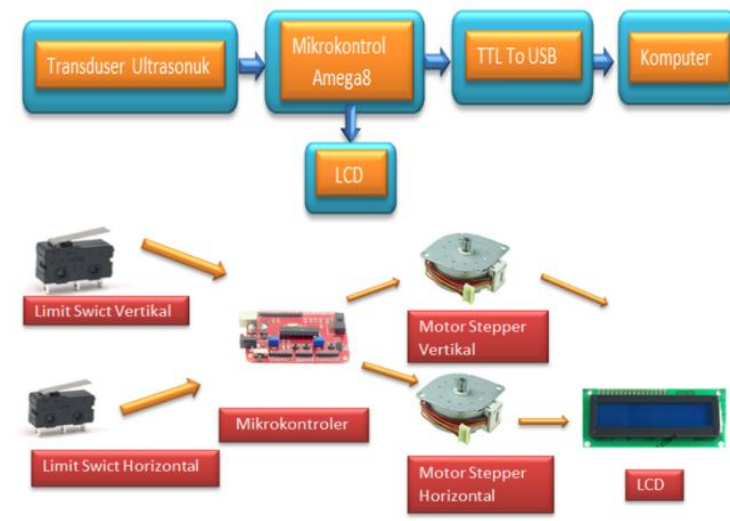

Gambar 3

Perancangan Alat Uji Non Destructive Test

Ultrasonic

\section{Hasil dan Pembahasan}

\subsection{Prosedur Pengujian}

1. Alat Ukur Standar a. Pasang benda kerja pada dudukan mesin

b. Pasang sensor ultrasonic pada bagian mesin yang sudah disiapkan

c. Nyalakan komputer dan buka program dari alat uji NDT ultrasonic

d. Gerakan sensor ultrasonic ke arah bagian benda kerja yang akan diuji.

e. Pada layar komputer akan muncak grafik dari cacat yang terdeteksi oleh sensor tersebut.

f. Simpat data hasil Pengujian

\subsection{Hasil Pengukuran}

Data di bawah ini merupakan hasil pengukuran pada alat uji NDT Ultrasonic pada dua material yang berbeda.

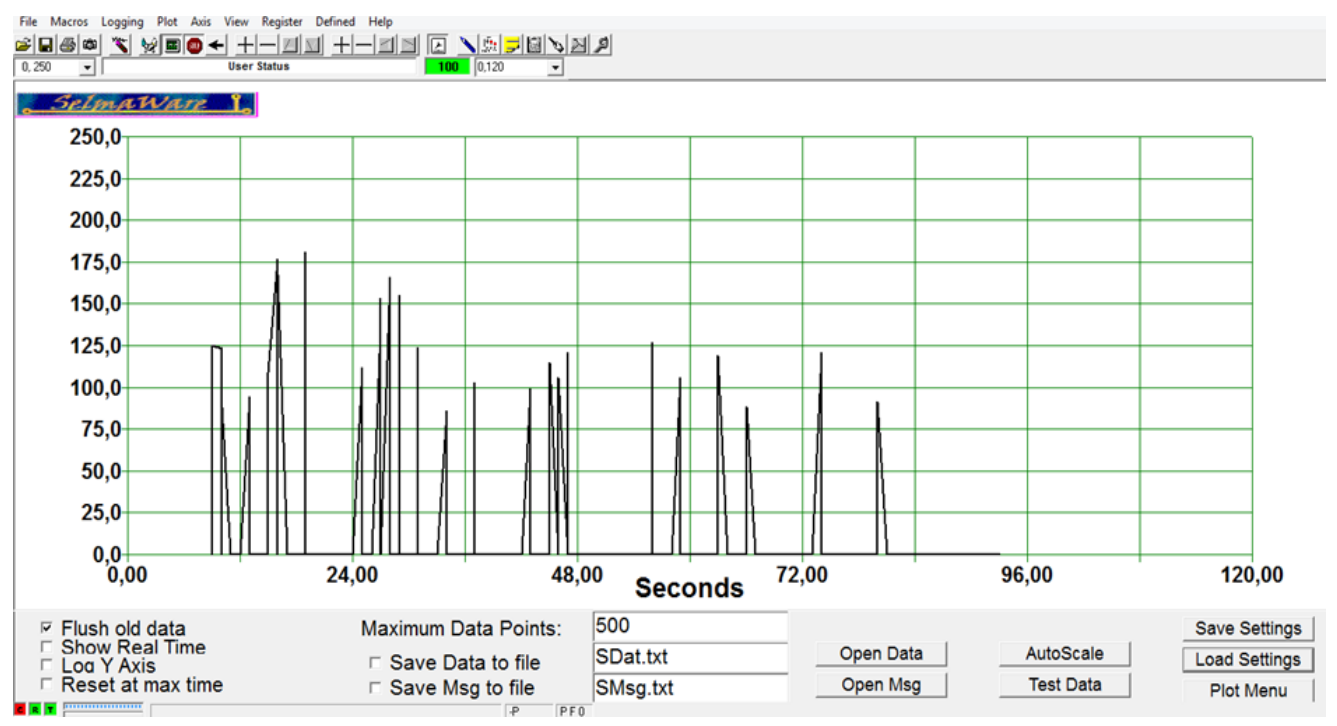

Gambar 4

Grafik hasil pengujian dengan alat NDT yang dibuat dengan material baja 


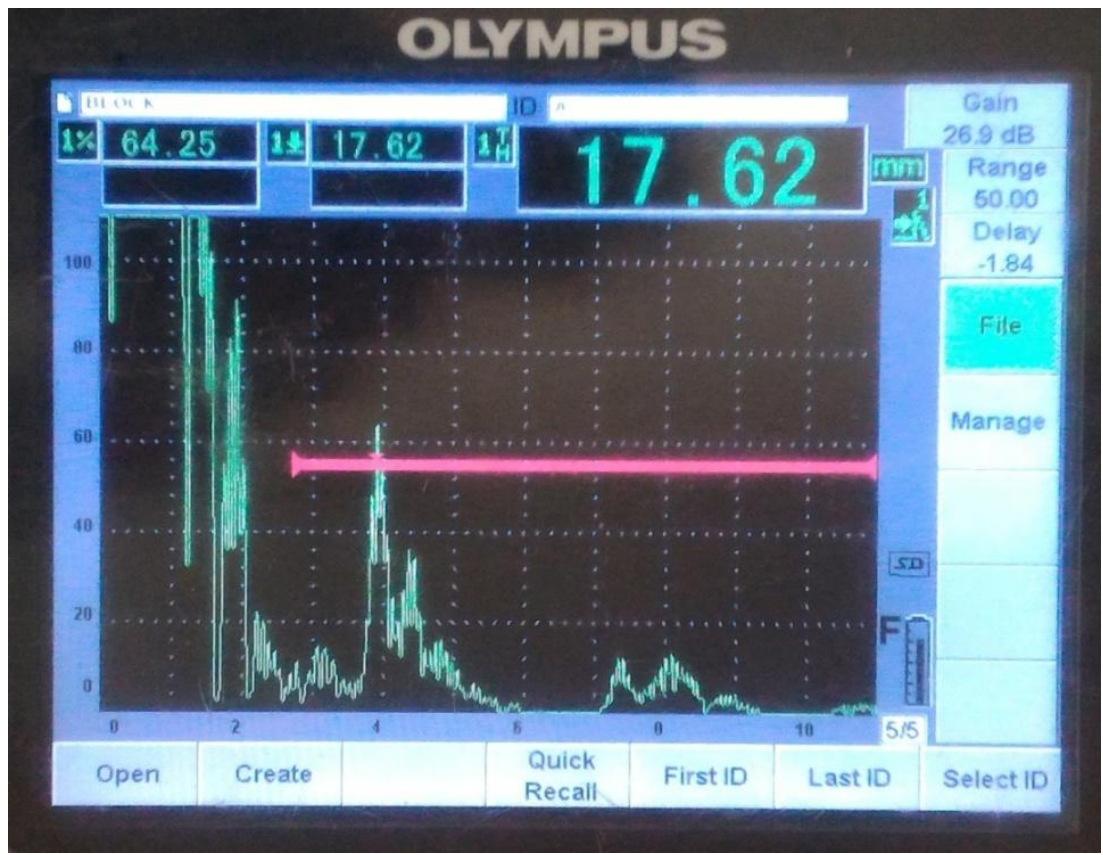

Gambar 5

Grafik hasil pengujian dengan alat NDT yang standar dengan material baja File Macros Logging Plot Axis View Register Defined Help

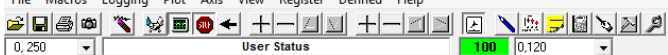

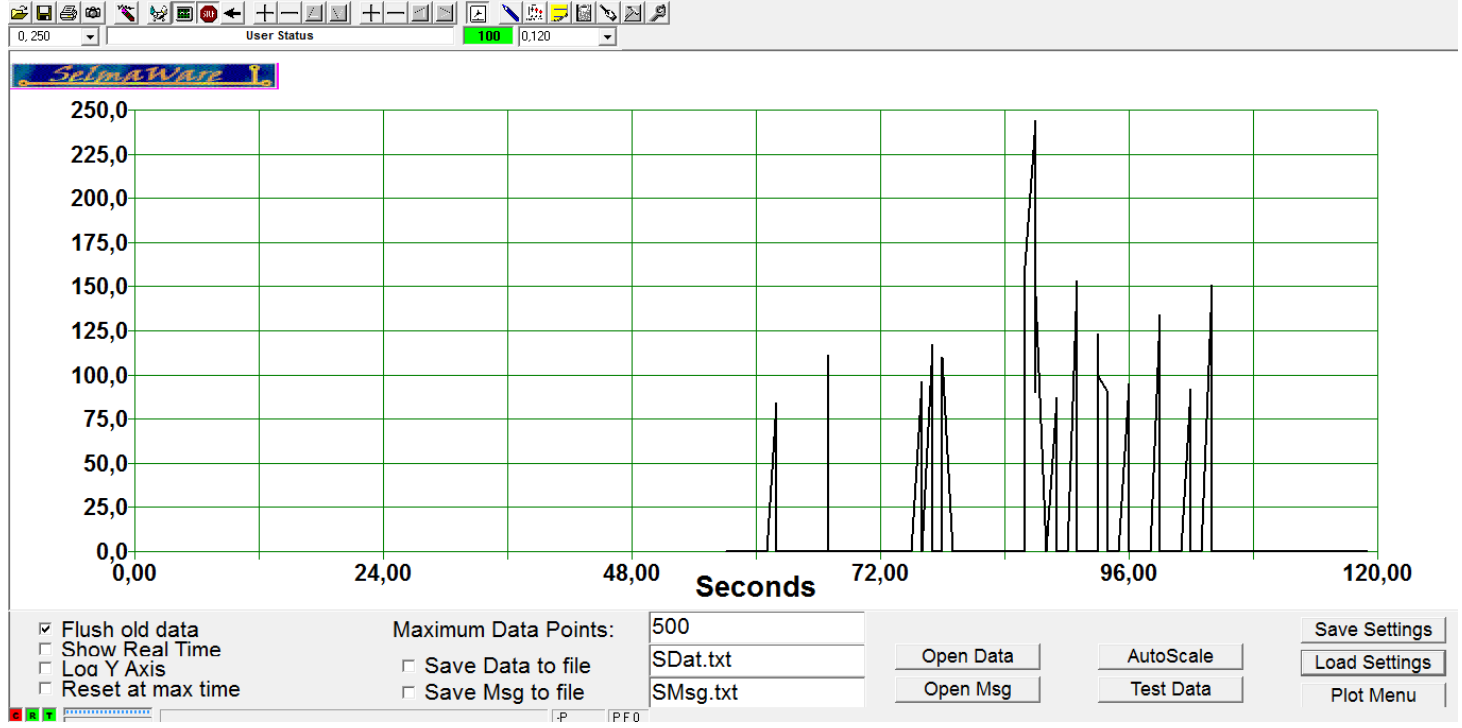

Gambar 6

Grafik hasil pengujian dengan alat NDT yang dibuat dengan material tembaga 


\section{Y ( Frekuensi)}

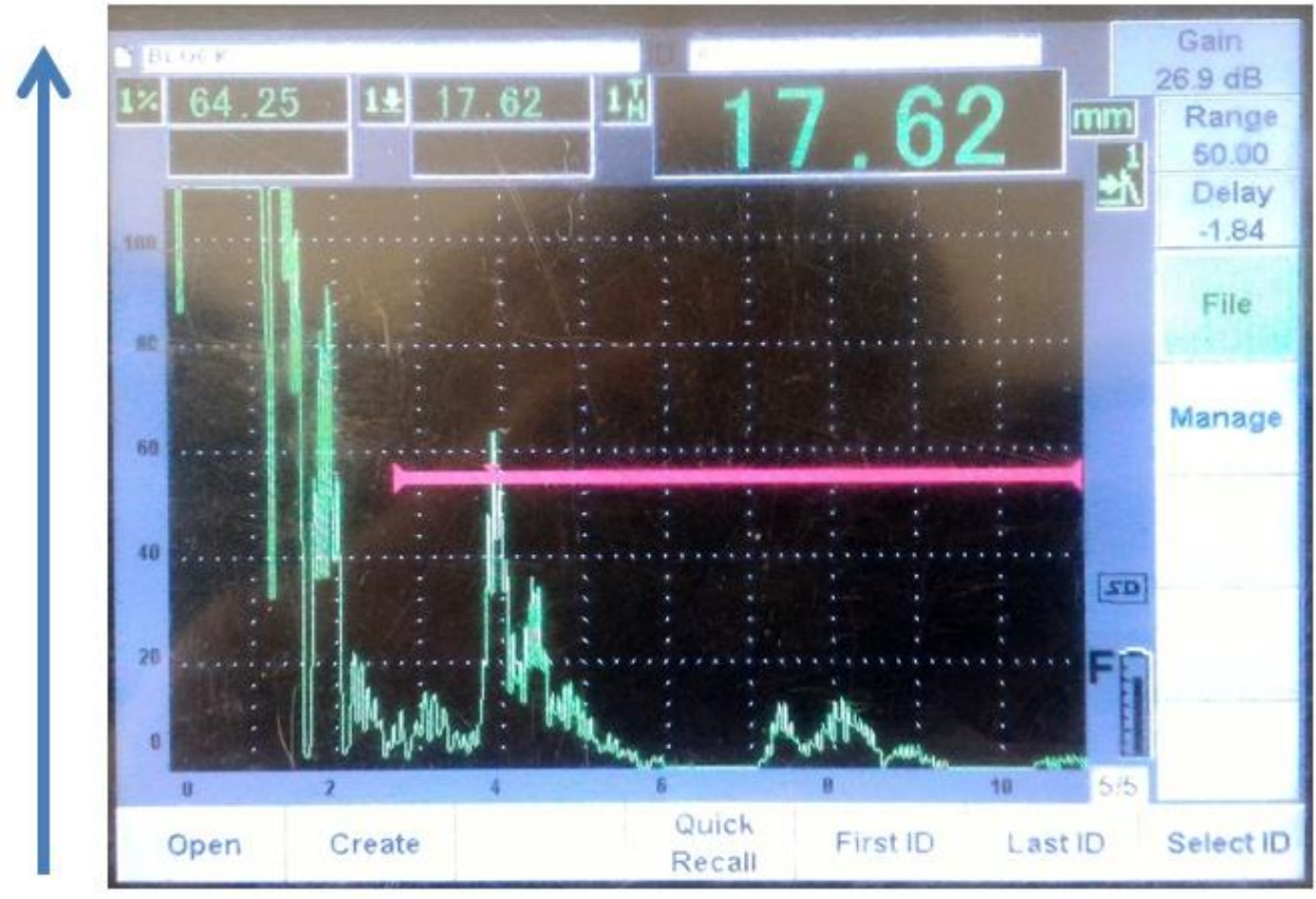

$\mathrm{X}$ (Waktu kecepatan rambat

\section{Gambar 7}

Grafik hasil pengujian dengan alat NDT yang standar dengan material tembaga

\section{Tabel 1}

Hasil perbandingan alat standar dan alat yang dibuat

\begin{tabular}{|c|c|c|c|c|c|c|c|}
\hline \multirow{2}{*}{ NO } & \multirow{2}{*}{ PARAMETER } & \multicolumn{2}{|c|}{ ALAT UKUR STANDAR } & \multicolumn{2}{c|}{$\begin{array}{c}\text { ALAT UKUR YANG } \\
\text { DIBUAT }\end{array}$} & \multicolumn{2}{c|}{ SELISIH \% } \\
\cline { 2 - 7 } & & BAJA & TEMBAGA & BAJA & TEMBAGA & BAJA & TEMBAGA \\
\hline 1 & $\begin{array}{c}\text { Panjang Gelombang } \\
\lambda\end{array}$ & 0,00168 & 0,00143 & 0,147 & 0,125 & $14,50 \%$ & $12 \%$ \\
\hline 2 & $\begin{array}{c}\text { Jarak } \\
\boldsymbol{S}\end{array}$ & 22932 & 15030 & 111720 & 30060 & $89 \%$ & $15 \%$ \\
\hline 3 & $\begin{array}{c}\text { Kemampuan Deteksi } \\
\varnothing\end{array}$ & 0,00084 & 0,000715 & 0,0735 & 0,0625 & $88 \%$ & $15 \%$ \\
\hline 4 & $\begin{array}{c}\text { Pengukuran Tebal bahan } \\
d\end{array}$ & 39 & 30 & 38,75 & 20 & $7 \%$ & $6 \%$ \\
\hline
\end{tabular}




\section{KESIMPULAN}

Alat ukur merupakan satu instrumen yang berfungsi untuk melihat suatu parameter hasil pengukuran. Alat ukur NDT merupakan salah satu bentuk alat ukur yang sering digunakan untuk melihat atau mengukur cacat logam atau material dengan tanpa merusak. Salah satu alat ukur NDT yang sering digunakan untuk mengukur cacat logam adalah jenis Ultrasonic. Proses pembuatan alat ini menggunakan Microcontroller.

Setelah alat tersebut selesai dibuat maka dilakukan pengujian dan kalibrasi, dari hasil kalibrasi yang dilakukan dengan menggunakan dua buah material yang berbeda yaitu tembaga dan baja didapat hasil sebagai berikut:

1. Perhitungan dengan metode Transversal

a. Kecepatan rambat untuk baja 3,13

b. Kecepatan rambat untuk tembaga 2,39

c. Panjang gelombang untuk baja $0,89 \mathrm{~mm}$

d. Panjang gelombang untuk tembaga $0,68 \mathrm{~mm}$

2. Alat ukur NDT yang dibuat

a. Kecepatan rambat untuk baja 3,13 b. Kecepatan rambat untuk tembaga 2,39

3. Alat ukur yang standar

a. Kecepatan rambat untuk baja 0,89

b. Kecepatan rambat untuk tembaga 0,59

Alat ukur yang dibuat mampu mengukur dengan ketebalan material 3 sampe $20 \mathrm{~mm}$ dan digerakan oleh 2 motor dengan daya motor 11,4 watt dan 19,5 Watt.

\section{DAFTAR PUSTAKA}

[1] American Society for Non Destructive Testing. (2002). Non Destructive Testing Inspector's Handbook. USA: American Society for Non Destructive Testing.

[2] Bartholommev, Davis. (1963). Electrical Measurements and Instrumentation. Boston: Allyn and Baccon, Inc.

[3] Ryder, John D. (1964). Electronic Fundamentals and Applications 3rd Edition. Englewood Clffe, NJ: Prentice-Hall, Inc.

[4] International Atomic Energy Agency, Vienna. (1999). Non Destructive 
Infomatek Volume 19 Nomor 2 Desember 2017 : 49 - 56

Testing: A Guidebook for Industrial Management and Quality Control Personnel. Austria. IAEA.

[5] William, D, Calister, Jr dan David, G, Rethwisch. (2009). Materials Science
And Engineering An Introduction Eighth Edition. America : John Wiley \& Sons, Inc. 